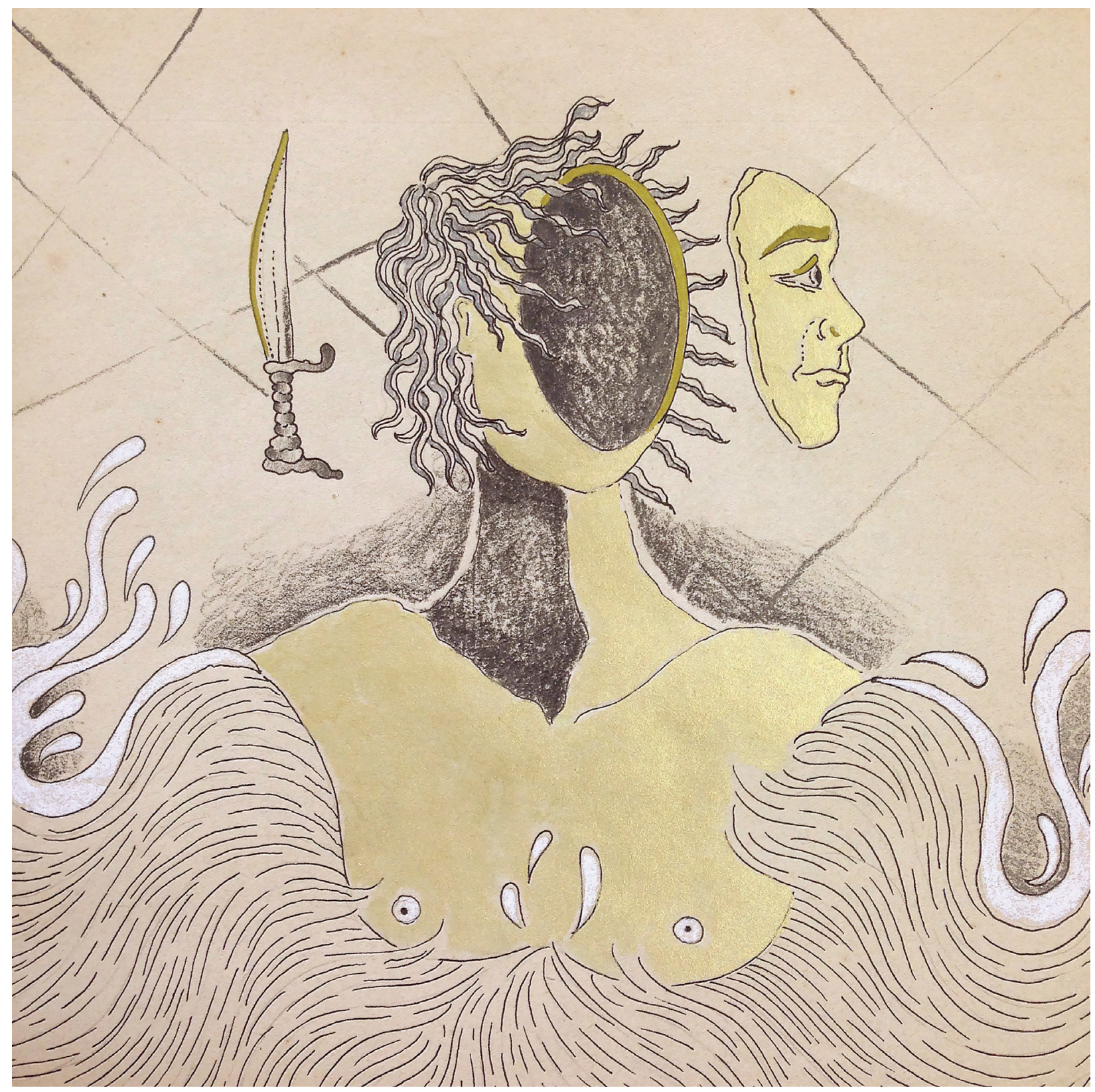

Figura 1 - Desrosto, da série Exercícios de Afogamento Breno Filo 2017 


\section{ROSTIDADE E EDUCAÇÃO}

\section{Resumo}

A máquina é social antes de uma configuração técnica, ela é produção antes de reprodução. A máquina se opõe à estrutura, ao mecanicismo e implica finitude, destruição e criação. O texto aborda a partir do pensamento de DeleuzeGuattari a ideia de rostidade, passando pelas configurações de subjetivação, bem como seus possíveis atravessamentos pelas dobras da educação. Como a educação pode fomentar o rosto? Que agenciamentos atravessam nessa produção maquínica de subjetivação? Como Deleuze-Guattari compreendem a produção da rostidade? Um rosto não é encontrar ou procurar, nem equivale a fomentar um conceito, mas ele passa por maquinismo e por um conjunto de vigilância. Ele também fomenta resistência, cava espaço de invenção, produz seus desdobramentos, configurando um verdadeiro criacionismo. Sobre ele, há uma guerra, uma labuta diária que leva a educação e seus processos a se arrastarem por dobras (im)possíveis. Não se chega em um rosto acabado, finalizado, sendo, portanto, uma batalha, uma guerra diária para a criação do rosto. Do mesmo modo que não há um solo unificado, mesmo na luta permanente para compor um rosto universalizante. Pela superfície do rosto navega a multiplicidade, permitindo embaralhar a máquina de codificação. Nesse cenário, o território da educação é fissurado por linhas de fuga, como forma de resistir ao padrão unificador.

\section{Palavras-chave:}

Máquina; Rostidade; Educação; Subjetividade; Deleuze; Guattari.

\section{Maria dos Remédios de Brito UFPA}

\section{Resumen}

La maquina es social ante de una configuración técnica ella es producción ante de reproducción. $L a$ maquina se opone a la estructura, al mecanismo e implica finitud, destruición y creación. El texto aborda el pensamiento de Deleuze- Guattari la idea de rostidad pasando a las configuraciones de subjetivación, bien como sus posibles pasajes por las doblas de la educación .¿Cómo la educación puede fomentar el rosto? ¿Qué agenciamientos atraviesan en esta producción maquinica de subjetivación? ¿Cómo DeleuzeGuattari comprende la producción de la rostidad? Un rosto no es encuentra o procurar, ni equivale en formentar un concepto más el pasa por maquinismo y por un conjunto de vigilancia. Él también fomenta resistencia, cava espacio de invención, produce sus desdoblamientos, configurando su verdadera creación. Sobre él hay una guerra, una labuta diaria que lleva a la educación y sus procesos a arrastraren por doblas (im)posibles. No llega en rosto acabado, finalizado, siendo, por lo tanto, una batalla de día, guerra diaria para la creación del rosto. A lo mismo modo que no hay un piso unificado, mismo en una luta permanente para construir un rosto universalizante. Por la superficie del rosto navega la multiplicidad permitiendo misturar la máquina de codificación. En este escenario, el territorio de la educación fijo por líneas de fuga, como forma de resistir al padrón unificado.

Palabras Llaves:

Maquina; Rostidad; Educación; Subjetividad; Deleuze; Guattari. 
Résumé

La machine est sociale avant d'être une configuration technique, elle est une production avant d'être une reproduction. La machine est opposée à la structure, elle implique la finitude, la destruction et la création. Ce texte aborde, à partir de Deleuze et Guattari, I'idée de visage - à trarvers les configurations de subjectivité -, aussi bien que les possibles passages de cette idée par les plis de l'éducation. Comment l'éducation peut favoriser le visage? Quels assemblages passent par cette production machinique de subjectivité? Comment Deleuze-Guattari comprennent la production du visage? Un visage n'est pas "trouver" ou "chercher", ni équivaut à "favoriser" un concept, mais il passe par une machinerie et par un ensemble de surveillance. Sur lui, il y a une guerre, il y a un labeur quotidien qui conduit l'éducation et ses processus à se glisser par des plis (im) possibles.

Mots-clés:

La machine; Visage; L'éducation; La subjectivité; Deleuze; Guattari.

\section{FRAGMENTO:}

A partir de inspiração dada pela leitura de Guattari, pode-se dizer não há como negar que se está em um sistema de modelização geral de poder que afirma e nega determinados papeis e determina espaços de maneira muito peculiar. Um poder que não é só permeado pelos objetos culturais ou sobre as possibilidades de suas manipulações, mas um poder cultural que pode ou não distinguir e se impor aos outros. Então, a questão é como criar outros espaços, outros modos que permitam com que os sujeitos sejam preenchidos não pela massificação, pelo empalhamento da vida, mas que possam inventar outras maneiras de se manterem em pé por si mesmo. Como criar novas produções semióticas em que a sociedade sobreviva sem tanta segregação e violência? Como fazer para que os modos culturais sejam difundidos, partilhados, sem serem rotulados como melhor ou pior, inferior ou superior? Como fazer para quebrar ou fissurar esse poder fundador e criar espaços de singularizações que trabalhe para cunhar outras sensibilidades? Como articular uma série de produções maquínicas que não se imponha uma sobre as outras?

\section{I}

É possível resistir à máquina abstrata de rostidade? Em que sentido essa máquina desvia de si mesmo como codificação dura? A educação produz essa maquinaria e como ela pode ser vista por outras linhas? O esforço do argumento considera essas questões.

\section{II}

A máquina ${ }^{1}$ não pode ser entendida a partir do mecanicismo e ou estruturalismo, ela se opõe a qualquer tipo de estrutura fechada, pois a "máquina implica uma relação de emergência, de finitude, de destruição e de morte" (GUATTARI, 1992, p. 71). Deleuze-Guattari discutem as máquinas técnicas, sociais, desejantes e abstratas, esta última é uma indomável máquina de produção de objetividadesujeitidade, emergente de um tempo atravessado pela heterogeneidade (GUATTARI, 1992). Cada máquina fomenta seus processos de ligações, de variações e de agenciamentos, porém, é importante notar que nas obras em conjunto, tais como $O$ anti-édipo e Mil Platôs, Deleuze e Guattari fazem esforços de amplitude e entendimento do que seja a máquina ${ }^{2}$, dando conta de ampliar e de produzir outros conceitos. Para os autores, há máquinas por todos os lados, em todas as partes, sendo essas conectáveis e acopláveis, emitindo fluxos e cortes.

A máquina é operada no sócius, no corpo, na alma. Para Guattari (1992), a história da humanidade passa por um verdadeiro criacionismo atravessado pelas concretudes e pelas virtualidades. Por mais que se busque uma unidade, o ser resulta sempre de sistemas de modelizações; sendo assim, essa configuração não passa por fixidade e nem por harmonia.

A problemática anteriormente evocada da função existencializante que poderiam assumir certos sistemas de modelização, certas cadeias discursivas [enunciados míticos, enunciados científicos, enunciados ideológicos, ritornelos, traços de rostidade] desviadas, de algum modo, de sua função significacional, denotacional e proposicional, nos leva a um reexame dos problemas do significado ou do conteúdo, da imagem, tudo que havia sido relativamente colocado entre parênteses na perspectiva estruturalista (GUATTARI, 1992, p. 72).

O que o autor levanta é uma mudança de relação lógica que na concretude existencial desencadeia efeitos discursivos, não discursivos, modos não unívocos. As configurações materiais passam por multiplicidades, atravessando o sujeito ${ }^{3}$, de modo que não se sabe efetivamente qual o elemento que o determinada ou qual o elemento que faz 
ou não parte dele. O sujeito é dobrado entre suas várias pregas, sendo o dentro ligado com a dobra do fora, como se fosse uma onda dobrada. Nada de interior com suas projeções. Há uma espécie de transversalismo fazendo com que "a entidade máquina escape à lógica em que os conjuntos discursivos permanecem sempre enquadrados" (GUATTARI, 1992, p. 73).

Esses processos maquínicos de produção não são fomentados por uma instância única de determinação dominante; além do mais, os processos são atravessados não hierarquicamente, pois as "máquinas são as formas conceituais com as quais se organiza a vida, se transforma o mundo, são as conexões materiais dentro dos quais se produz a subjetividade" (NEGRI, 2010, p. 102). Com isso, no que se refere às subjetividades, elas são concebidas como produto e produção de agenciamentos diante das relações homemmáquina, rosto-máquina, que formam o seu conteúdo, fugindo ao aprimoramento da forma, fazendo-a modular. Todo esse maquinismo é atravessado nas sociedades tomando ramificações potentes naquilo que Guattari (2010) chama de sociedades capitalistas e tecnológicas que engendram modos, formas, condutas, valores de consumo por uma multiplicidade de signos e significações conduzindo os processos de subjetivação para ramos de interesses particulares.

A transversalidade que perpassa os processos de subjetivação, na atualidade, obriga a se pensar fora das estruturas fechadas, pois há configurações de produção semióticas diversas, que passam pelos componentes familiares, religiosos, de meio ambiente, de arte, de psicologia, de educação, entre outros; assim como elementos fabricados pelos jornais, pelas revistas, pelos blogs, pelas redes sociais, pelas novelas, pelo cinema etc.

Há também um jogo informacional de signos ${ }^{4}$ que gira por todos os lados, que fomenta e escapa de certas axiomáticas da linguagem postas como padrão informativo, ainda que seja, acima de tudo, performática; mas, sendo assim, nem sempre o sócius pode ser dobrado pela linguagem. Não há língua em si, não há língua homogênea, a não ser quando é enquadrada em uma posição política. Contudo, há todo um esforço de produção maquínica para se igualar, pois maior o menor padrão de linguagem depende, efetivamente, de uma relação de poder. Para Guattari e Rolnik (2010, p. 39):

Esses processos são duplamente descentrados. Implicam funcionamento de máquina de expressão que podem ser tanto de natureza extrapessoal. Extra-individual [sistemas maquínicos, econômicos, sociais, tecnológicos, icônicos, ecológicos, etológicos, de mídia, ou seja, sistemas que não são mais imediatamente antropológicos], quanto de natureza infra-humana, infrapsíquica, infrapessoal [sistema de percepção, de sensibilidade, de afeto, de desejo, de representação, de imagem e de valor, modos de memorização e de produção de ideias, sistemas de inibição e de automatismos, sistema corporais, orgânicos, biológicos, fisiológicos e assim por diante].

É importante ressaltar que todos esses processos fazem funcionar e produzir a subjetividade, pois esta não é um centro nuclear de totalidade. Portanto, diante de processos tão dinâmicos e, ao mesmo tempo, conectivos, é possível colocar em funcionamento uma variedade de instâncias maquínicas que não se sabe direito por onde podem ser atravessadas. Por exemplo, as novas tecnologias levam a pensar que há uma produção homogênea de subjetividade, mas se sabe que há uma tendência cada vez mais heterogênea na produção desses processos que são insuspeitos por toda a velocidade que sofre a sociedade atual.

No sistema produtivo capitalista, os possíveis buracos de desordem são violentados e abafados para que nada fuja ao controle. Uma composição heterogênea carrega trocas múltiplas e maquinam produção de grupos, de coletivos, oferecendo aos sujeitos possibilidades de dobras, de diversificação para compor e recompor seus processos de corporeidade, que podem ou não sair, ou a engendrar impasses diversos, bem como podem compor ou recompor alguma forma de individuação .

As máquinas de produção de subjetividade variam; ao longo do tempo, nos "sistemas mais tracionais a subjetividade é fabricada por máquinas mais territorializadas" (GUATTARI; ROLNIK, 2010, p. 32). Nas sociedades atuais, a partir da leitura de Guattari, seus fluxos de produção são violentos; a moda, o comércio, a mídia fazem um verdadeiro trabalho de montagem de rostos e corpos que obriga a subjetividade se reconfigurar violentamente para todos os lados. Os rostos vão tomando formas, mas há rostos que desfazem a forma, configuram (de) formações e problematizam encontros e apresentam tensões para outros rostos e corpos. 
Há operações diversas que oferecem diferentes transplantes que não procedem e por meio da ideia de uma subjetividade arcaica, criam-se "novas modalidades de subjetivação do mesmo modo que um artista plástico cria novas formas a partir da palheta que dispõe" (GUATTARI, 1992, p. 17).

\section{III}

No texto intitulado "Ano Zero", DeleuzeGuattari(1996) mostram uma poderosa máquina abstrata produtora de rosto que escava os buracos que atravessam a subjetividade. Essa máquina opera por conexões complexas, por agenciamentos concretos de toda ordem. Eles também afirmam que ela percorre caminhos virtuais, que se diferenciam em suas variações e deslocamentos. Assim, uma máquina abstrata “[...] é ela mesma um território, novamente coberto de dobras, sombras variadas e alternativas possíveis" (NEGRI, 2010, p. 105).

Nessa configuração produtiva, uma subjetividade é arborescência-rizoma e dobra na superfície (NEGRI, 2010). Na sua produção, não se sabe efetivamente o peso e a leveza que desencadeia, mas o agenciamento produtivo a atravessa, o conflito é permanente, havendo uma realização infinita no acontecimento (NEGRI, 2010), pois a maquinaria não para de girar, havendo sempre formas de injetar representações. Formam-se imagens de mães, de filhos, de gostos, de crianças, de mulheres, de homens, havendo sempre modificações que criam maneiras de articulação no trabalho, na família, na escola, nas instituições. Há aí toda uma maquinaria produtiva de controle social e até mesmo instancias psíquicas que configuram forma de ser no mundo.

A máquina abstrata é todo um movimento de produção; nela há o processo de construção e desconstrução, tendo a capacidade imanente de criar, de entrar em diferentes planos, de anular diferentes linhas, de traçar redes com a capacidade de territorializar e de desterritorializar. A máquina abstrata deve ser posta como capacidade de diferenciação, pois produz encadeamentos, bem como tem a capacidade de configurá-los. Sendo assim, não há linearidade, também não há um peso de estado de coisas fixas. Se há processualidade, virtualidades, dobramentos, plasticidades, podese fazer a opção pelo entendimento de que não há totalizações fechadas em si que possam demarcar um universo de referência; elas são como a "máquina abstrata, no entanto real e individual, cujas peças são os agenciamentos ou os indivíduos diversos que agrupam, cada um, uma infinidade de partículas sob uma infinidade de relações mais ou menos compostas" (DELEUZE; GUATTARI, 1997, p. 39).

A máquina abstrata "se instaura transversalmente aosníveismaquínicosmateriais, cognitivos, afetivos, sociais" (GUATTARI, 1992, p.46). Ela também pode ser entendida como uma montagem heterogênea, assim como aquilo que extrai, que coloca em funcionamento uma variedade de ligações. Ela nos "heterogeniza fora de qualquer traço unificador" (GUATTARI, 1992, p. 51). A abstração, assim, é entendida como a capacidade de criar, entrando em diferentes planos, indicando o poder produtivo da abstração, diante da possibilidade de extrair e de produzir encadeamentos, fugindo dos limites e de estados de coisas. Ela traça forças, desejos que possibilitam inventar diariamente novas práticas, novas paixões, novas mercadorias, novas tecnologias, novos rostos.

A questão parece ser de composição e não de estrutura ou de organização. Há aí traços de lentidão, de repouso, de velocidades, de movimentos que atravessam o corpo e a subjetividade. Então, a demanda é dos elementos que poderão chegar, ou não, de forma rápida ou lenta, que possa operar travessias ou saltos diante dessa produção. 0 corpo está sempre maquinado, entrando em uma variedade de zonas complexas em que os sujeitos são manipulados, vigiados, controlados e deslocados. Para isso, é preciso produzir uma multiplicidade de técnicas que disciplinam, formam, conduzem, apanhando os sujeitos por todos os lados.

A vida encontra-se percorrida em um plano, mesmo que se diga fixo; há todo um movimento de abstração que a retalha, entrando nesse ou naquele agenciamento individuado de velocidade, de movimento ou de lentidão que compõe o funcionamento maquínico. Esse maquinismo ocupa uma imensa máquina abstrata que com infinitas conexões faz com que um corpo seja envolvido sob essa ou aquela conjunção, composição, decomposição. Um corpo não se faz sem um rosto, pois há uma ação máquina que faz com que todo ele seja produzido. Mas um rosto está sempre para ser maquinado e não efetivamente concluído. 
Deleuze-Guattari (1996) afirmam que nas sociedades primitivas, partindo do texto "Ano Zero..." [com xamãs, guerreiros e caçadores], nada ou quase nada passaria pela ideia de rosto. Até nas possessões [as almas, os espíritos, os devires animais], o rosto não era visto como um universal, nem mesmo aquele do homem branco. Os primitivos preferiam a corporeidade, a animalidade, a vegetabilidade ao rosto.

Entre nós, nas formações sociais, com seus agenciamentos de poder, o rosto é visto como significância ${ }^{6}$ e subjetividade. A significância não existe sem um muro branco, no qual há a escrita dos signos e das redundâncias, assim como a subjetividade não existe sem um buraco negro no qual se aloja a consciência e suas redundâncias (DELEUZE; GUATTARI, 1996, p 31). O "rosto não é um invólucro exterior àquele que fala, que pensa ou que sente" (DELEUZE; GUATTARI, 1996, p.32). O rosto carrega a significância, zonas de frequência, delimitam um campo que neutraliza a rebeldia ou melhor...

Os rostos não são primeiramente individuais, eles definem zonas de frequência ou de probabilidade, delimitam um campo que neutraliza antecipadamente as conexões rebeldes às significações conformes. Do mesmo modo, a forma da subjetividade (DELEUZE; GUATTARI, 1996, p. 32).

As subjetivações se tornam vazias se não possuem rosto, e seus lugares produzem ressonâncias. O rosto é o produtor de uma redundância, ele é a moldura, a tela, o quadro no qual os desenhos significantes são postos que neutralizam comunicações violentas, rebeldes. Por isso, ele "escava o buraco de que a subjetivação necessita para atravessar" (DELEUZE; GUATTARI, 1996, p.32). Nesse sentido, os autores alertam que:

$\mathrm{O}$ rosto é mesmo redundância. E faz ele mesmo redundância com as redundâncias de significância ou frequência, e também com as de ressonâncias ou de subjetividade. O rosto constitui o muro do qual o significante necessita para ricochetear, constitui o muro do significante, o quadro ou a tela (1996, p. 32).

Contudo, é possível dizer que o significante e o significado não se movimentam sozinhos e nem mesmo a subjetividade cava só o buraco pelo qual atravessa o rosto. Os rostos também não se constituem sozinhos; suas concretudes nascem de uma máquina abstrata da rostidade [máquina abstrata de codificação]. Sem dúvida, essa máquina procura assumir determinados papéis de escolhas e de seleção. Ela constrói e destrói, ela rejeita e aceita rostos. Aqueles rostos com ares suspeitos são desprezados, postos em segunda ordem de entendimento e de percepção. Parece haver sempre uma suspeita, uma zona lacunar suspensa, paisagem vaga, buraco aberto, pontos de virtualizações impossíveis.

\section{[...] os rostos se distribuem em todo sistema, os traços de rostidade se organizam. E entretanto ainda, essa máquina abstrata pode certamente funcionar em outra coisa que não rostos; mas não em qualquer ordem, nem sem razões necessárias (DELEUZE; GUATTARI, 1996, p. 34).}

Os rostos são montados, ao mesmo tempo em que são dobrados, desfeitos. Há todo um mecanismo abstrato que passa e que não se sabe efetivamente onde passa a concretude ou seu estado de coisa.

\footnotetext{
A máquina abstrata de rostidade assume um papel de resposta seletiva ou de escolha: dado um rosto concreto, a máquina julga se ele passa ou não passa, se vai ou não vai, segundo as unidades de rostos elementares [...] cada instante a máquina rejeita rostos não-conformes ou com ares suspeitos. Mas somente em certo nível de escolha. Pois será necessário produzir sucessivamente desvios padrão de desviança para tudo aquilo que escapa às correlações biunívocas, e instalar relações binárias entre o que é aceito em uma primeira escolha e o que não é tolerado em uma segunda, em uma terceira (DELEUZE;GUATTARI, 1996, p. 44-45).
}

Ela se movimenta e vai distribuindo a rostidade em todo o sistema e, assim, a rostidade vai se organizando, tomando determinados contornos e determinadas expressões, bem como certas coordenadas binárias por meio do "é assim" ou"não é assim", "sim" ou "não", que demarca categorias que entram ou não em um certo campo de tolerância. Do mesmo modo, essas categorizações podem indicar um inimigo que pode ou não ser banido. Logo, a máquina abstrata de rostidade encontra, esquadrinha, faz sua inscrição, mesmo que em certas situações possa ser provisória.

Pode-se dizer, segundo Deleuze e Guattari, que essa máquina não se contenta em traçar a rostidade e nem tem preocupação com os casos singulares; ela procede ao modo de fomentar a normalidade e a universalidade. Um exemplo pode ser dado a partir dos autores, que esclarecem que o racismo não procede por exclusão, mas...

por determinações das variações de desvianças, em função do rosto Homem branco que pretende 
integrar em ondas cada vez mais excêntricas e retardadas os traços que não são conformes, ora para tolerá-los em determinado lugar e em determinadas condições, em certos guetos, ora para apagá-los no muro que jamais suporta a alteridade [...]. Do ponto de vista do racismo, não existe exterior, não existem as pessoas de fora. Só existem pessoas que deveriam ser como nós, e cujo crime é não o serem. (DELEUZE; GUATTARI, 1996, p. 45, grifo meu).

Se não há um foro "de", mas um como "nós", é devido à produção padrão do rosto que não visa às individuações. Sendo assim, sobre essa questão se pode desenvolver uma escala de variações que não suportam o exterior, a diferença, gerando todas as formas de intolerância, de horror e pavor frente à alteridade, em que a diferença é subjugada à semelhança e a generalidade. Então, pode-se notar que são agenciamentos de poder bem particulares que qualificam determinados protótipos de significâncias e de subjetividades. Nessa relação, há sempre um agenciamento déspota e autoritário.

A máquina abstrata de rostidade escreve cada um em um quadriculado e o muro branco não para de crescer; portanto, ela produz a ordenação, as vizinhanças, e procura detectar desvios, violações e não tende a se preocupar com a singularização, mas busca promover os universais. $\mathrm{E}$ a rostidade escreve-se no muro, desenha o organismo, faz a escrita, tende a promover o significado, pois:

A máquina abstrata que irá produzir rosto. Mas a operação não pára ai: a cabeça e seus elementos não serão rostificados sem que o corpo inteiro não o possa ser, não seja levado a sê-lo, em um processo inevitável. A boca e o nariz, e antes de tudo os olhos, não se tornam uma superfície esburacada sem convocar todos os outros volumes e todas as outras cavidades do corpo [...]. O rosto não tem o papel de modelo ou de imagem, mas de sobrecodificação para todas as partes descodificadas. (DELEUZE; GUATTARI, 1996, p. 35, grifo meu)

A tela, o muro, anseiam por um buraco central pelo qual deve ordenar e formatar outros rostos. Essa lógica da unidade tende a delinear as arborescências, as instalações binárias, dicotômicas, em que o significado e a subjetividade podem realmente tornarem-se concebíveis em solo firme. Por isso, o receio de cada ponto maquínico, discursivo, linguístico, semiótico ou de subjetividade, abrir outras conexões nômades e resistentes ao padrão universal e de controle, mesmo estando sempre submetido à mutação permanente.
A máquina abstrata de rostidade tem como objetivo entrar na ordem molar e bloquear os fluxos; assim, nenhuma perspectiva de uma máquina nômade que esteja além do significado e do significante, que vá paraalém das representações, não ébem vista. O fora efetivamente deve ser protegido, enclausurado, na perspectiva da máquina de rostidade. Ela diz não a qualquer tipo de tempestade exterior e tende a arrastar os "sujeitos" para um olho central, mesmo havendo fugas por todos os lados.

Essa superfície que serve como plano de montagem sempre percorre uma clandestinidade, pois os traços da rostidade não se deixam subsumir por completo; então, pode-se dizer que no rosto há sempre um por vir, uma abertura à possibilidade de ser desfeito, desarranjado. O rosto também atravessa uma paisagem, que não pode ser entendida apenas como um meio, mas como desterritorialidade. Há várias ligações sobre essa ideia de rostopaisagem. A educação cristã traça um rosto, governa paisagem, faz toda uma manobra com o corpo, com os sentidos, fomenta uma rigorosa disciplina, configura toda uma paisagem que faz do rosto uma pedagogia.

O close do rosto no cinema também imprime certa pedagogia, traçando uma paisagem que define tela câmera, luz, composição, foco. Até nos romance o rosto dos personagens traçam planos-paisagens. Não há rosto que "não envolva uma paisagem desconhecida, inexplorada, não há paisagem que não se povoe de um rosto amado ou sonhado, que não desenvolva um rosto por vir" (DELEUZE; GUATTARI, 1996, p. 38). Essa parece ser a linha em que o rosto permanece incompleto, aberto a outras vias que não sejam ordinárias. Isso que dizer que ele passa por uma maquinaria, autoritária ou não autoritária, negadora do outrem, ou não, ou quem sabe esteja em um entre-paisagem, no meio em que possa se expor como resistência à identidade fixa.

Um rosto é um corpo, mesmo sem estar efetivamente no corpo, pois comporta um entre, "ele é um meio, o rosto é o 'e', numa superfície, no 'meio', e estar no meio, não é estar nem acima nem abaixo, nem dentro nem fora, como uma linha onde se cruzam ou encontram um mundo interior e um mundo exterior" (GIL GODINHO, 2010, p.68). Sendo assim, ele exige certos estados de alma. Ele também faz traçados que remetem a mundos que "singulares e únicos formam o rosto, 
numa superfície onde se exibe um índice da sua presença. Um rosto é um anúncio, uma produção social, um espaço 'sobrecodificado', rede complexa de interpretações com uma unidade exclusiva de expressão. É mesmo antes de mais expressivo" (GIL GODINHO, 2010, p.68).

Com isso, um rosto que é também um corpo, ou melhor, uma superfície não pode nunca encontrar uma forma efetiva, sendo aberto, esburacado, pode estar fechado, alegre, triste, cansado, revigorado, pode apresentar também um olhar faminto, uma boca sem riso, uma pele enrugada. É possível entrar e sair do rosto ou mesmo fazer dele uma zona de indiscernibilidade. Produzir uma rostidade nunca é tranquilizador, pois há variações, experimentações, passagens, desmontes, violações, lamurias, guerras. Como diz Gil e Godinho (2010, p.69), "não é um encontro tranquilo, pode ser mesmo uma transgressão. 0 espaço pode ser rasgado, revertido, adaptar-se a montagens de qualquer natureza. 'Abrimo-nos às coisas', 'abrimos o coração ou a alma', abrimos os olhos que são as 'janelas da alma'". Tudo isso não deixa de ser atravessado pelos devires, o rosto, com isso, é atravessado por lugares, meios que o conduzem a certas territorialidades e desterritorialidades. 0 rosto é essa superfície sem pontos, mas apenas converge em si traçados de toda ordem.

\section{IV}

Com o que fora dito acima, indaga-se: o que a educação tem a ver com essa poderosa máquina abstrata de rostidade? A educação poderia ser entendida como um campo de rostidade? Ora, é sabido que a educação é uma questão cultural, política, ligada ao sócius e ao poder. Com isso, a educação não deixa de ricochetear o rosto, ela mesma é um rosto com suas superfícies que não deixam de fomentar significações. Ela instala comandos por todos os lados, disciplina corpos, fomenta normas, institui condutas, sempre cavando um buraco da subjetividade ou buscando um muro, um buraco para que o eu seja instalado, esse eu que é tão caro para alguns.

O muro educativo diz que: "você deve ser ordenado, interpretado, subjulgado ou o seu corpo deve ser articulado, caso não, pode ser um depravado ou anormal. Você é um significante para ser significado, portanto, você não é um desviante. Você será um sujeito, sujeitado, para não ser um vagabundo". O espaço escolar não é separado de uma educação docilizada, por isso, talvez, a gramática comum nunca é separável de uma educação do rosto, se aliando, assim, à máquina abstrata de rostidade, pois submete a expressão para uma subjetividade comum.

Segundo Deleuze, quando "a professora explica uma operação às crianças, ou quando Ihes ensina sintaxe, não lhes dá propriamente informações, comunica-Ihes injunções, transmite-Ihes palavras de ordem" (2004, p. 34). Com isso, há toda uma promoção à caça aos devires, pois o ideal é o requerimento de corpos e subjetividades disciplinados, para pensar a partir de Foucault (1987). Esse corpus autoritário determina a produção do rosto em escala social, pois opera por todo o corpo, não havendo, portanto, rosto e sujeitos prévios.

Até mesmo a infância é governabilizada em todos os seus trajetos pela pedagogia escolar, pois não há espaço para que a criança se veja como não datada, esquadrinhada, mesmo sem saber o que seja tudo isso. Para a criança, há todo um processo de rosto que deve ser definido dentro dos muros da escola. Essa definição acompanha a forma de conduta que o professor deverá ter, a formação dentro da sala de aula, o passo a passo nas leituras infantis, dos brinquedos, das brincadeiras etc. Há aí todo um cuidado de formar valores, subjetividade, cofigurar moralidade. Contudo, as crianças não deixam de ser os maiores cartógrafos, desfazedores de rostos.

Isso quer dizer que a educação não só produz um rosto, como também faz esse processo com o corpo inteiro; há toda uma operação que vai produzindo outras cavidades do corpo. A cabeça, as mãos, os ouvidos, a boca, a linguagem, o seio, o ventre, as pernas, os braços, os pés, a roupa, os cabelos: tudo isso vai sendo tomado pelos processos de rostidade. Há todo um sistema de operação eficaz da razão que desencadeia essa montagem, passando por aparatos semióticos, discursivos e linguísticos poderosos.

O rosto sempre vai precisar dessa máquina abstrata que não se contenta em codificar somente a cabeça. Mas como a educação desencadeia essa máquina de rostidade? Quando determinados agenciamentos de poder entram em jogo, o poder tem necessidade de produção. Tal produção está envolvida por uma série dispersa de movimentos 
que se operam, que se agitam, delineando linhas e fissurando outras, ou todas ao mesmo tempo.

Agenciamento concreto de poder despótico e autoritário - desencadeamento da máquina abstrata de rostidade, muro branco-buraco negroinstalação de uma nova semiótica de significância e de subjetivação, nessa superfície esburacada. É por isso que não cessamos de considerar dois problemas exclusivamente: a relação do rosto com a máquina abstrata que o produz; a relação do rosto com os agenciamentos de poder que necessitam dessa produção social. O rosto é uma política (DELEUZE; GUATTARI, 1996, p. 50).

A educação não deixa de estar presente no interior dessa máquina quando entra no campo da modelização, pois, politicamente, agencia o poder padrão normativo, bem sucedido [uma máquina de controle da vida que busca sempre a correção, a consciência, a razão, a moral]. De todos os modos, busca a normalidade dos corpos, uma imagem comum a todos os rostos. É difícil sair do buraco negro da subjetividade, e se é tentado a permanecer todos os dias encerrado em um rosto comum ou em um asilo confortável para se dormir e descansar.

A educação não mede esforços. Para isso, há todo um esquema arborescente instalado que esquematiza, separa, disciplina e organiza vidas, sexo, costume, modo de ser e ver etc. Ela se esforça para controlar até mesmo o aprender, com urgência de criar métodos, formas, maneiras de conduzir a criança para um lugar seguro. Com isso, a razão deve ser vigida, a inteligência corrigida, a memória reforçada. Toda uma aprendizagem da cognição é formada para que a criança exercite seus processos inventivos em um padrão modelar.

Quando essa criança promove variações, uma equipe de pedagogos e de psicólogos se mantém à espreita, nada pode ficar fora do lugar, mesmo os processos inventivos, fabuladores que tanto fazem as crianças. Mapas são produzidos, imaginação voa, mãos rabiscam muros, cadeiras, portas; porém, dentro do espaço escolar tudo isso é imediatamente corrigido, medicalizado ou patologizado, mas as variações continuam. Contudo, segundo diz Deleuze (2004), o pior de tudo isso não é a esterilização que atravessa a educação, mas é o esmagamento de tudo aquilo que passa pelo meio, pelo entre. Ora, existe em toda parte multiplicidades que não se deixam binarizar, dicotomizar, paralisar. Existem centros com vazamentos que não se deixam aglomerar. "Há linhas, que não se reduzem ao trajeto de um ponto, e que escapam à estrutura, linhas de fuga, de devires" (DELEUZE, 2004, p. 38).

Por isso, para além dessa unidade despótica, entende-se que o rosto é inumano, desde o início, ele é close, com suas superfícies brancas, com seus buracos negros, com suas cavidades, com seu vazio, seu tédio, sua angústia, seus desejos, suas ruínas, suas alegrias, seus desamparos, suas aberturas impossíveis. Se há um destino para o homem, esse será escapar do rosto universal para tornar-se a si mesmo.

Para além da educação do rosto unívoco, se anseia por um modo de educação imperceptível e clandestino, traçado pelas menoridades, por campos de fendas de individuações. O muro branco deve ser quebrado, pois no rosto há um mundo inexplorado, mundo de futuros-presentes, instantes, velocidades vitais, que nenhuma lógica linear poderá navegar.

Não é tranquilizador escapar, porque a todo o momento não se sabe para onde ir, por qual linha escapar, em que meio entrar, qual fissura atravessar, em que onda nadar. É algumas vezes um terror. Por isso, buscar um rosto não é encontrar ou procurar, não é fomentar um conceito, mas um conjunto de experimentações, pois ao rosto não se chega, não se chegará, já que ele não para de deslizar. Há toda uma vigilância, mas há também um processo viajante e sobre ele há uma guerra, uma labuta diária. O que pode um rosto? Experimentações éticas, políticas... Ele atrai censura, mas também desejo, liberdade.

Para um rosto, há todo tipo de corpus que não deixa a experimentação sossegada. Assim, o rosto está sempre no meio desde que ele se compreendeu como maquinação. Prudência, a regra da experimentação do rosto para comportar os [im] possíveis. Sim, pois a máquina abstrata se perde dela mesma por suas multiplicidades de agenciamentos, fazendo conexões que percorrem as individuações ao invés das subjetividades. Assim, o que pode a educação a favor dessas passagens? O que pode a educação quando não sustenta essa superfície, pois nela os buracos deixam vazar experimentos desviantes? 0 rosto, mesmo, é uma superfície esburacada, abrigando 
sempre fissuras, passagens. Por isso, nem sempre as perguntas devem ou podem ser respondidas.

De outro modo, quando o entendimento fica obscuro, vale permitir o corpo sentir certos intervalos, percorridos por lentidões, latitudes, longitudes, conjuntos de afectos não subjetivados. Assim, é possível ter instantes, um dia, uma hora, um segundo de individuações que alimentam uma estação que se pode achar de uma vida. Isso independe da duração ou mesmo da regularidade. Um rosto? Maquinações que se distribuem por todos os lados, mas que não cessam de produzir seus intervalos, seus hiatos, seus vazios criativos para, quem sabe, ponderar um pouco de possível.

\section{NOTAS}

1. O termo é trabalho por Félix Guattari no artigo de 1969, intitulado "Máquina e Estrutura", publicado em Change, n. 12, Suel. O autor procura fazer a distinção entre o que seria entendido por máquina e estrutura (Cf: GUATTARI, F. Psicanálise transversalidade. Ensaios de análise institucional. Trad. Adail Ubirajara Sobral, Maria Stela Gonçalves. Aparecida/SP: Ideias \& Letras, 2004). Também lança discussão sobre a problemática do sujeito e estrutura, indivíduo e estrutura. Há toda uma contextualização dessa discussão posta por François Dosse na sua obra biografia cruzada Gilles Deleuze e Félix Guattari. Cito-o: "Assim, Guattari falará de "Máquina e estrutura". O alvo é designado, e sua intervenção poderia muito bem se intitular "Máquina contra a estrutura". Ele identifica ali os ângulos mortos da grade de análise estrutural, e a noção de máquina que apresenta como operatória é destinada a pensar o recalcado do estruturalismo, à articulação dos processos de subjetivação e do acontecimento histórico. É o primeiro texto que se refere a Deleuze, a quem ainda não conhece, mas do qual leu e apreciou a tese, Diferença e Repetição, e Lógica do Sentido [...]. Contra a estrutura, que se define por sua capacidade de trocas de elementos particulares, a máquina proveria da repetição, mas no sentido entendido por Deleuze, isto é, a repetição como diferença [...]. O surgimento da máquina marca uma data, um corte não homogêneo [...] A essência da máquina é justamente essa operação de desprendimento de um significante como representante, como diferenciante, como um corte causal, heterogêneo na ordem das coisas estruturalmente estabelecidas [...]. É o sujeito que interessa a Guattari, e ele o concebe como clivado, lacerado, na intersecção, no entredois, em tensão entre estrutura e máquina" (Cf: DOSSE, F. Gilles Deleuze \& Féliz Guattari: biografia cruzada.Tradução de Fátima Murad. Porto Alegre: Artmed, 2010, p.189-190).

2. Em Mil Platôs n. 5, os autores afirmam que a máquina abstrata poderia ser dita que " num primeiro sentido, não existe a máquina abstrata, nem máquinas abstratas que seriam como Ideias platônicas, transcendentes e universais, eternas. As máquinas abstratas operam em agenciamentos concretos" [...] "são sempre singulares e imanentes [...] as máquinas abstratas ignoram as formas e as substâncias. Por isso são abstratas, mas também é esse o sentido rigoroso do conceito de máquina. As máquinas excedem toda mecânica [...]. As máquinas abstratas consistem em matérias não formadas e funções não formais [...]. Abstratas, singulares e criativas, aqui e agora, reais embora não concretas, atuais ainda que não efetuadas; por isso, as máquinas abstratas são datadas e nomeadas [máquina abstrata-Einstein, máquina abstrata-Webern, mas também Galileu, Bach ou Beethoven, etc.]. Não que remetam a pessoas ou a momentos efetuados; ao contrário, são os nomes e as datas que remetem às singularidades das máquinas, e a seu efetuado [...]" (DELEUZEGUATTARI, 1997, p. 227-228).

3. O termo sujeito não está ligado aos aportes tradicionais, sendo concebido como a instância primeira e última do conhecimento ou como pura consciência pré-reflexiva, foco de unidade, de expressividade do saber unificador. O texto toma preferência pelo tratamento de subjetividade, esta não sendo passiva de totalização ou de centralidade. A subjetividade é efetivamente fabricada na cartografia social e cultural.

4. Aquilo que nos faz pensar, o que nos rouba a paz, que força o pensamento.

5. Dizem Guattari e Rolnik: "Seria conveniente dissolver radicalmente os conceitos de indivíduo e subjetividade. Para mim, os indivíduos são resultados de uma produção de massa. 0 indivíduo é serializado, registrado, modelado [...]. A subjetividade não é passível de totalização ou de centralização. Uma coisa é a individuação do 
corpo. Outra é a multiplicidade de agenciamentos da subjetivação: a subjetividade é essencialmente modelada no registro do social. [...] Parece oportuno partir de uma definição ampla da subjetividade, como a que estou tentando, para, em seguida, considerar como casos particulares os modos de individuação da subjetividade: momentos em que a subjetividade diz eu [...], momentos em que a subjetividade se reconhece num corpo ou numa parte de um corpo, ou num sistema de pertinência corporal coletiva (GUATTARI; ROLNIK, 2010, P. 40-41). Nessa perspectiva, uma observação relevante, não se está falando de uma subjetividade fincada na representação Moderna, em que a ideia de sujeito remetia a uma categoria fundadora, identitária. A ideia de subjetividade pressupõe uma maquinação, algo criado, produzido ou mesmo fabricado por várias determinações sociais, culturais, históricas, econômicas, políticas e que também faz parte de um campo de variação constante. Dessa forma, para além da ideia de um sujeito centrado, monolítico, produtor do conhecimento, Guattari e Deleuze pensam a ideia de subjetividade sem sujeito, fomentada por produção e modelada, sendo a mesma, transformada e adaptada.

6. Antonio Negri, interpretando os autores, diz que a significância "é a expressão do desejo" (Negri, 2010, p. 104).

\section{REFERÊNCIAS}

DELEUZE, G.; PARNET, C. (2004). Diálogos. Tradução: de José Gabriel Cunha. Lisboa: Relógio D'água editores.

DELEUZE, G; GUATTARI, F. (1996). Mil Platôs: capitalismo e esquizofrenia, v. 3, Tradução: Aurélio Guerra Neto et alii. Rio de Janeiro: Editora 34.

fOUCAULT. M. (1987). Vigiar e Punir. Nascimento da Prisão. Petrópolis: Vozes.

GUATTARI, F. (1992). Caosmose: um novo paradigma estético; Tradução: Ana Lúcia de Oliveira e Lúcia Cláudia Leão. São Paulo: Ed. 34.

GUATTARI, F.; RONILK, S. (2010). Micropolítica: cartografias do desejo. Petrópolis: RJ.

GIL GODINHO, A. (2010). Como desfazer para si

o seu próprio rosto? São Paulo, SP: Cadernos de Subjetividade. Publicação anual do Núcleo de Estudos e Pesquisas da Subjetividade, do Programa de Estudos Pós-Graduados em Psicologia Clínica da PUC-SP. p. 69-78.

NEGRI, A. (2010). Sobre Mil Platôs. In: Revista Lugar Comum (p. 95-112). Rede Universidade Nômade.

\section{SOBRE A AUTORA}

Maria dos Remédios de Brito é professora da Universidade Federal do Pará. Graduada em Filosofia pela Universidade Federal do Pará; Mestre e Doutora em Filosofia da Educação pela Universidade Metodista de Piracicaba; Pós-Doutora em Filosofia da Educação pela Universidade Estadual de Campinas. 